\title{
Modified Natural Zeolites as Catalysts for Catalytic Reduction of NO with CO-Main Components of Exhaust Gases
}

\author{
Giorgi Maisuradze ${ }^{1}$, Shota Sidamonidze ${ }^{1}$, Lali Akhalbedashvilii ${ }^{2}$ and Revaz Kvatashidze ${ }^{2}$ \\ 1. Department of Informatics, Mathematics and Natural Sciences, Holy Apostle St. Andrew the First-Called Georgian University of \\ Georgian Patriarchate, Tbilisi 0162, Georgia \\ 2. Analytical Centre "Geoanalitica”, Alexander Tvalchrelidze Caucasian Institute of Mineral Resources, Ivane Javakhishvili Tbilisi
} State University, Tbilisi 0128, Georgia

\begin{abstract}
The study of oxidized-reduced properties of modified natural zeolites from deposits of Georgia-clinoptilolite and mordenite in reaction of reduction $\mathrm{NO}$ with $\mathrm{H}_{2}, \mathrm{NH}_{3}, \mathrm{CH}_{4}$ and especially $\mathrm{CO}$ was carried out for the purpose to obtain effective catalyst for afterburning of toxic components of automobile exhaust. The activity of zeolites essentially depends on nature of cation and temperature of reaction and slightly depends on structure of zeolite and ratio of reactants. The introduction of copper and iron ions in preliminary decationated clinoptilolite and mordenite causes growth of conversion degree of nitrogen and carbon monoxides almost on a degree, especially in low temperature interval. The reaction between NO and $\mathrm{CO}$ molecules proceeds in coordinative sphere of TM cations through formation of nitrosyl and carbonyl complexes.
\end{abstract}

Key words: Natural zeolites, NO, CO, reduction, automobile exhaust.

\section{Introduction}

One of global ecological problem is the pollution of the environment with products of oxidation of nitrogen, carbon and sulfur, contained in exhaust gases and especially in ejected gases of undertaking and thermoelectric power stations $\left(\mathrm{NO}_{\mathrm{x}}, \mathrm{CO}, \mathrm{NH}_{3}\right.$ and hydrocarbons etc.). This problem has been recently more actually because of destruction of ozone layer with nitric oxide except the formation of smog and "acid" rains.

Each year, by burning of hydrocarbons, hundreds of millions tons of four main pollutants are released into the atmosphere-nitrogen oxides, carbon monoxide(II), sulfur dioxide and particulate matter. For example, carbon monoxide-one of the major toxins released into the atmosphere as a result of natural disasters (volcanic eruptions, wildfires) and

Corresponding author: Lali Akhalbedashvili, Ph.D., main research field: catalysis on zeolites. human activity (gas emissions from industrial enterprises and transport).

Therefore, in the earth's atmosphere, it is thrown mostly carbon monooxide-300 million tonnes (of which 56\%-62\% are accounted for motor vehicles), 50 million tons of $\mathrm{NO}_{\mathrm{x}}$ released with the combustion products and 25 million tons of emissions of the chemical industry. The proportion of nitrogen oxides and carbon emissions is about $60 \%[1,2]$. However, automobile exhaust gases contain approximately 280 compounds, the most toxic not only nitrogen(II) and carbon(II) oxides, but formaldehyde and phenol, 3,4-carcinogenic benzpyrene and other polyaromatic substances, compounds of inorganic lead.

To decide the automotive emissions' problem and contamination of air, it has been developed a variety of methods and ways that permitted to reduce the amount of emissions or decrease their toxicity.

These methods are the absorption and adsorption, thermal afterburning, biochemical and plasma 
methods and the universal thermo-catalytic cleaning methods. The advantage of catalytic methods is that they allow to convert contaminants into harmless, providing an opportunity to recycle gases with low initial concentrations, achieve high degrees of purification, carry out the process continuously, and avoid the formation of secondary pollutants. The use of catalytic methods are often limited by the difficulty of finding and manufacture the suitable for continuous operation, and quite cheap and effective catalysts. The catalytic oxidation of $\mathrm{CO}$ to $\mathrm{CO}_{2}$ - the most realistic and promising method for purifying gases from $\mathrm{CO}$, but if afterburning of $\mathrm{CO}$ carries out simply, reduction of $\mathrm{NO}_{\mathrm{x}}$ to $\mathrm{N}_{2}$ will be a difficult task. It is known that nitric oxide (NO) is thermodynamically instable with respect to $\mathrm{N}_{2}$ and $\mathrm{O}_{2}$ : (i.e. for reaction $2 \mathrm{NO} \rightarrow \mathrm{N}_{2}+\mathrm{O}_{2} \Delta \mathrm{G}<0$ ). However, the most obvious method of removing $\mathrm{NO}$ is catalytic decomposition. From a great number of heterogeneous contacts studied in the conversion of nitrogen oxides, the most effective catalysts till now were $\mathrm{Cu}$-containing zeolites [1-6].

Existing methods for the catalytic purification of waste gases from nitrogen oxides are based on the reduction of $\mathrm{NO}_{\mathrm{x}}$ with such compounds as ammonia, hydrocarbons, carbon monoxide and others. For a practical use in this process, only those catalysts are suitable, which remain active in the presence of oxygen, and being a competitor of the interaction of $\mathrm{NO}_{\mathrm{x}}$ with carbon monoxide [7]. Therefore, a large excess of oxygen greatly reduces $\mathrm{NO}_{\mathrm{x}}$ conversion. However, it found that on some catalysts with rise of oxygen concentration, the conversion of carbon monoxide is increased [8].

In practice, the catalytic purification is the most effective and realized by the use of expensive metals, such as platinum, rhodium and palladium, deposited on neutral carriers (about $50 \%$ of extractive platinum is used up on catalytic neutralizers). They best meet the requirements of the gas purification catalysts: high catalytic activity at low temperatures and high volumetric speeds of passing mixtures and insensitivity to the majority of catalyst poisons. Carriers have a honeycomb structure and are mostly made from synthetic ceramic.

As substitutes for catalysts of platinum group, they have been studied intensively complex oxide systems. Highly active catalysts are oxidizing phases with perovskite structure and spinel. Among them are considered to be perspective cuprates of elements: alkaline earth, rare earth and heavy elements, which show high catalytic activity in the conversion of carbon monoxide and nitrogen oxides in non-toxic products [9-11]. Some of them possess high-temperature superconductivity, their structure and many properties have been well studied, which allows more specifically examine some features of their structure due to the catalytic activity. However, the practical application of the cuprates and other perovskites is constrained by the fact that, despite the significant number of researches, questions of the nature of their catalytic activity is not entirely clear [11].

Among the other various adsorbents and catalysts (oxides of titanium, vanadium, intermetallic compound of platinum group and others), synthetic and natural zeolites are more active and selective with respect to corrosive $\mathrm{CO}, \mathrm{NO}_{\mathrm{x}}, \mathrm{SO}_{2}$ and $\mathrm{H}_{2} \mathrm{~S}$ etc.. From the synthetic zeolite materials, the promising was to use the neutralizers obtained by supporting of $\mathrm{Fe}$ or $\mathrm{Cu}$ ions on pentasils: almost $90 \% \mathrm{NO}_{\mathrm{x}}$ is converted into $\mathrm{N}_{2}$ at $350{ }^{\circ} \mathrm{C}$ [12-14].

Natural zeolites - a relatively new type of minerals whose use on an industrial scale began only in the 60-ies of XX century. Up to this time in the industry, people usually used the synthetic analogs of natural zeolites. Practical use of natural zeolites induced by discovery in the early 1960s of large deposits in the United States, Japan, former Soviet republics and some other countries. The unique properties of zeolites as adsorbents and ion exchangers are determined by the structural features of the crystal lattice, in which up to $50 \%$ of the volume, there are 
interstices and channels. Experimental-industrial testing of the properties of zeolites proved the possibility of their widespread use as catalysts in a variety of industries, agriculture and ecology. Such natural minerals as clinoptilolite, shabazite, mordenite are characterized by high stability against acids, mechanical and thermal loading, which are accessible and cheap in comparison with oxide catalysts.

Thereby, the main aim of the work is the investigation of possibility of nitric oxides' catalytic neutralization with carbon monoxide, ammonia, hydrogen and methane on cation-modified natural zeolites, such as clinoptilolite and mordenite.

The possibility of catalytic neutralization of $\mathrm{NO}$ and $\mathrm{CO}$ by using inexpensive, accessible and easy-regenerating catalysts, prepared on the basis of clinoptilolite has been studied in Tbilisi State University for several years and described in a number of papers [15-18]. During the last years, the modernization of catalysts was carried out mainly at the expense of the simplification of preparation methods and search and modification of other natural zeolites.

\section{Experimental Part}

\subsection{Catalysts Preparation}

The catalysts were prepared by treatment with complex salts of iron and copper of preliminary decationated and dealuminate zeolite clinoptilolite (CL) from deposits of Dzegvi (Georgia) and mordenite (MOR) from Ratevani deposit (Georgia). The content of initial samples there are in Table 1.

Reagents - solutions of $\mathrm{HCl}$ and $\mathrm{KOH}\left(\mathrm{NH}_{4} \mathrm{OH}\right)$, freshly made ammoniac solutions of $\mathrm{Cu}$-contained, Fe-contained salts with different concentration. The chemical composition of samples was determined by chemical analysis, AAS and flame photometry. The state of surface and the preservation of the crystal structure of obtained systems were controlled by $\mathrm{X}$-ray with $\mathrm{Cu} \mathrm{K} \alpha$ emission line.

The applied processing method was as $[15,17]$ :

(1) Washing of grinded natural samples of CL and MOR with weak alkali solutions at room temperature and drying;

(2) Threefold processing with $1 \mathrm{~N}$ hydrochloric acid at 353-373 $\mathrm{K}$ during one hour;

(3) Washing and drying at $393 \mathrm{~K}$;

(4) Repeated processing with decinormal solutions of ammoniac complexes of corresponding cations;

(5) Washing and drying at $393 \mathrm{~K}$ and thermal treatment at 653-673 $\mathrm{K}$ during 6 hours in dry air.

The chemical composition is in Table 1.

\subsection{Study of Catalytic Activity}

Catalytic measurements were carried out on catalytic microflow installation with immovably fixed catalyst bed and varying temperature within 423-773 K, reagent flow rate in the range $200-500 \mathrm{~h}^{-1}$, volume and degree of samples granulation from $1.0 \mathrm{~mm}$ to $0.25 \mathrm{~mm}$. The catalyst was preliminary dehydrated in dry air flow at $723 \mathrm{~K}$.

Table 1 Chemical composition of studied zeolites.

\begin{tabular}{|l|l|}
\hline Sample & Chemical content in oxide form \\
\hline CL & $0.51 \mathrm{Na}_{2} \mathrm{O} \cdot 0.17 \mathrm{~K}_{2} \mathrm{O} \cdot 0.75 \mathrm{CaO} \cdot 0.30 \mathrm{MgO} \cdot 0.16 \mathrm{Fe}_{2} \mathrm{O}_{3} \cdot \mathrm{Al}_{2} \mathrm{O}_{3} \cdot 8.48 \mathrm{SiO}_{2}$ \\
\hline DeCL* & $0.12 \mathrm{Na}_{2} \mathrm{O} \cdot 0.15 \mathrm{~K}_{2} \mathrm{O} \cdot 0.44 \mathrm{CaO} \cdot 0.18 \mathrm{MgO} \cdot 0.09 \mathrm{Fe}_{2} \mathrm{O}_{3} \cdot \mathrm{Al}_{2} \mathrm{O}_{3} \cdot 19.88 \mathrm{SiO}_{2}$ \\
\hline $\mathrm{HCL}$ & $0.43 \mathrm{Na}_{2} \mathrm{O} \cdot 0.18 \mathrm{~K}_{2} \mathrm{O} \cdot 0.76 \mathrm{CaO} \cdot 0.28 \mathrm{MgO} \cdot 0.11 \mathrm{Fe}_{2} \mathrm{O}_{3} \cdot \mathrm{Al}_{2} \mathrm{O}_{3} \cdot 5.34 \mathrm{SiO}_{2}$ \\
\hline CuDeCL & $0.09 \mathrm{Na}_{2} \mathrm{O} \cdot 0.11 \mathrm{~K}_{2} \mathrm{O} \cdot 0.11 \mathrm{CaO} \cdot 0.12 \mathrm{MgO} \cdot 0.36 \mathrm{CuO} \cdot 0.06 \mathrm{Fe}_{2} \mathrm{O}_{3} \cdot \mathrm{Al}_{2} \mathrm{O}_{3} \cdot 19.00 \mathrm{SiO}_{2}$ \\
\hline CuFeDeCL & $0.06 \mathrm{Na}_{2} \mathrm{O} \cdot 0.08 \mathrm{~K}_{2} \mathrm{O} \cdot 0.06 \mathrm{CaO} \cdot 0.12 \mathrm{MgO} \cdot 0.36 \mathrm{CuO} \cdot 0.22 \mathrm{Fe}_{2} \mathrm{O}_{3} \cdot \mathrm{Al}_{2} \mathrm{O}_{3} \cdot 22.04 \mathrm{SiO}_{2}$ \\
\hline MOR & $0.11 \mathrm{~K}_{2} \mathrm{O} \cdot 0.42 \mathrm{Na}_{2} \mathrm{O} \cdot 0.47 \mathrm{CaO} \cdot \mathrm{Al}_{2} \mathrm{O}_{3} \cdot 9.4 \mathrm{SiO}_{2}$ \\
\hline DeMOR* & $0.06 \mathrm{~K}_{2} \mathrm{O} \cdot 0.19 \mathrm{Na}_{2} \mathrm{O} \cdot 0.34 \mathrm{CaO} \cdot \mathrm{Al}_{2} \mathrm{O}_{3} \cdot 8.6 \mathrm{SiO}_{2}$ \\
\hline CuDeMOR & $0.16 \mathrm{~K}_{2} \mathrm{O} \cdot 0.16 \mathrm{Na}_{2} \mathrm{O} \cdot 0.26 \mathrm{CaO} \cdot 0.14 \mathrm{CuO} \cdot \mathrm{Al}_{2} \mathrm{O}_{3} \cdot 8.6 \mathrm{SiO}_{2}$ \\
\hline CuFeDeMOR & $0.16 \mathrm{~K}_{2} \mathrm{O} \cdot 0.16 \mathrm{Na}_{2} \mathrm{O} \cdot 0.22 \mathrm{CaO} \cdot 0.11 \mathrm{CuO} \cdot 0.08 \mathrm{Fe}_{2} \mathrm{O}_{3} \cdot \mathrm{Al}_{2} \mathrm{O}_{3} \cdot 9.4 \mathrm{SiO}_{2}$ \\
\hline
\end{tabular}

* De-decationated sample. 
As model used the gas mixtures with content: $\mathrm{NO}-0.2-1.5$ vol.\%; $\mathrm{CO}-0.6-2.0$ vol.\% and water vapor- 5.00 vol. $\%$. The total content of $\mathrm{N}_{2} \mathrm{O}, \mathrm{NO}_{2}$ and $\mathrm{O}_{2}$ was less than 2 vol.\%.

Preliminary treatment of catalyst was carried out by dehydration in a flow of dry air at $523 \mathrm{~K}$. The partial pressure of one of reagents is varied during the experiment, at the same time, the partial pressure of others is stayed permanent, but the common pressure stays practically constant at the expense of insertion in system of the defined amount of air. The composition of initial reagents and obtained products was analyzed by gas chromatography, using helium as carrier gas, molecular sieve $13 \mathrm{X}$ and Porapac $\mathrm{G}$ or $\mathrm{R}$ as chromatographic phases. The rate of NO reduction was calculated on the base of volume flow of gas mixture and content of $\mathrm{N}_{2}$ and/or $\mathrm{N}_{2} \mathrm{O}$ in mixture after reactor.

\section{Results and Discussion}

3.1 The Temperature Dependence of Catalytic Activity of Studied Samples in Reduction of NO

According to obtained data $\mathrm{CL}$ and in the less degree MOR in natural, hydrogen and cation-modified forms display the activity in following reactions: $\mathrm{NO}_{\mathrm{x}}$ $+\mathrm{CO}(1) ; \mathrm{NO}_{\mathrm{x}}+\mathrm{NH}_{3}(2) ; \mathrm{NO}_{\mathrm{x}}+\mathrm{H}_{2}$ (3) and $\mathrm{NO}_{\mathrm{x}}+$ $\mathrm{CH}_{4}$ (4). In low-temperature region, the sharply differ on reducing ability, but in high-temperature interval, initial CL and MOR are more active in selective catalytic reduction of NO by ammonia (Fig. 1). This activity is explained by occurrence of impurities of Transition Metals (TM) in natural zeolites, especially $\mathrm{Fe}^{3+}$ in oxide or cationic form. These results are in accordance with literature data [19] that $\mathrm{Fe}^{3+}$ cations are more active in reaction (2). The introduction of copper cations in CL and MOR give two effects - reduce the temperature of conversion and in the same time increase the conversion degree. The study of reactions (1-4) on Cu-exchanged samples shows that these reducing agents on their activity located in line: $\mathrm{CO}>$ $\mathrm{NH}_{3}>\mathrm{H}_{2}>\mathrm{CH}_{4}$ (Fig. 2).

Practically, the same catalytic data were obtained for $\mathrm{CuDeCL}$, promoted with $\mathrm{Fe}^{3+}$ ions (Fig. 3). $\mathrm{CuFeDeCL}$ shows the smallest activity in reaction (4) and $\mathrm{NO}_{\mathrm{x}}$ decomposition. Reactions (2) and (3) are characterized with parallel run of activity curves. Two temperature intervals were determined in NO reduction with $\mathrm{CO}$ : from $400 \mathrm{~K}$ till $573 \mathrm{~K}$, the linear dependence of conversion degree on temperature is observed, then sharp rise of conversion, which reaches $92 \%$ at $623 \mathrm{~K}$ (Fig. 3).

The authors find that introduction of $\mathrm{Cu}^{2+}$ ions in Fe-contained zeolite causes the displacement of $\mathrm{Fe}^{3+}$ in more hard-to-reach positions in zeolite channels, but $\mathrm{Fe}^{3+}$ ions, inserted in $\mathrm{Cu}$-exchanged $\mathrm{CL}$ and MOR, vice-versa, can't shift copper cations. Since the copper

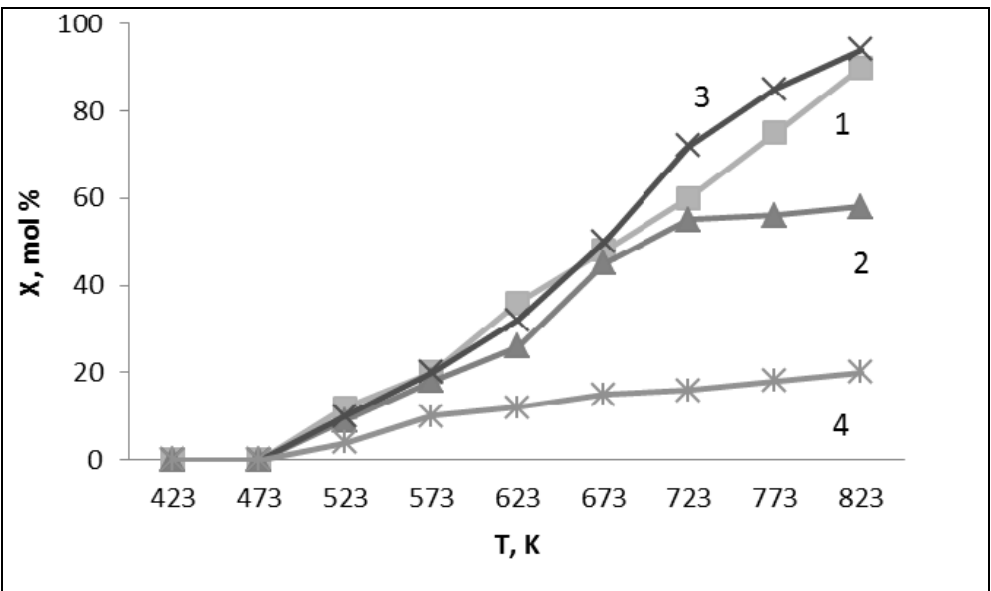

Fig. 1 The temperature dependence of converse degree in reduce of $\mathrm{NO}$ with $\mathrm{H}_{2}(1), \mathrm{CO}(2), \mathrm{NH}_{3}(3)$ and $\mathrm{CH}_{4}(4)$ on initial CL. 


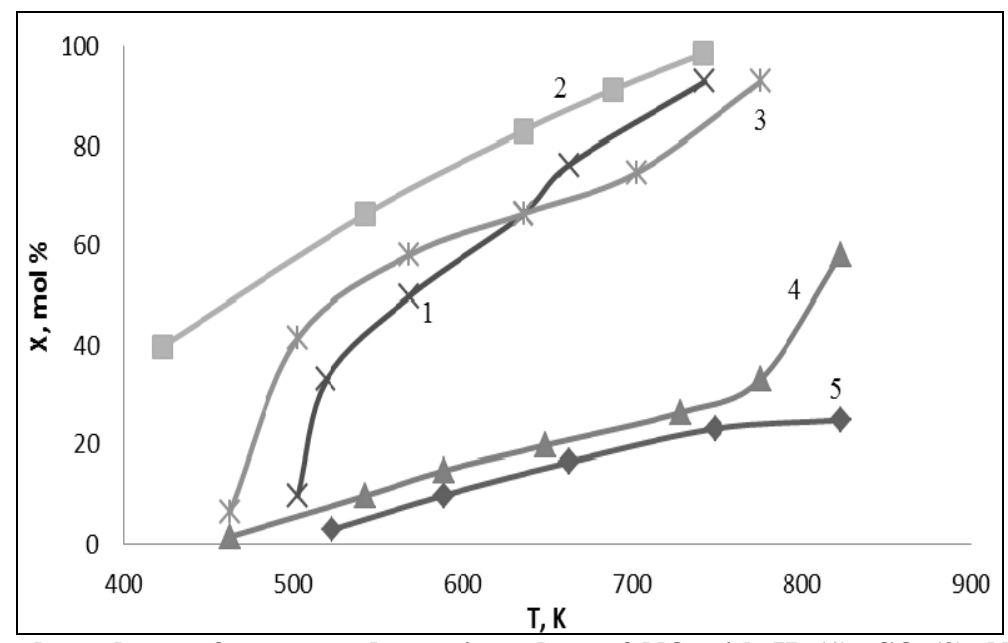

Fig. 2 The temperature dependence of converse degree in reduce of $\mathrm{NO}$ with $\mathrm{H}_{2}(1), \mathrm{CO}(2), \mathrm{NH}_{3}(3), \mathrm{CH}_{4}(4)$ and $\mathrm{NO}_{\mathrm{x}}$ decomposition (5) on CuDeCL.

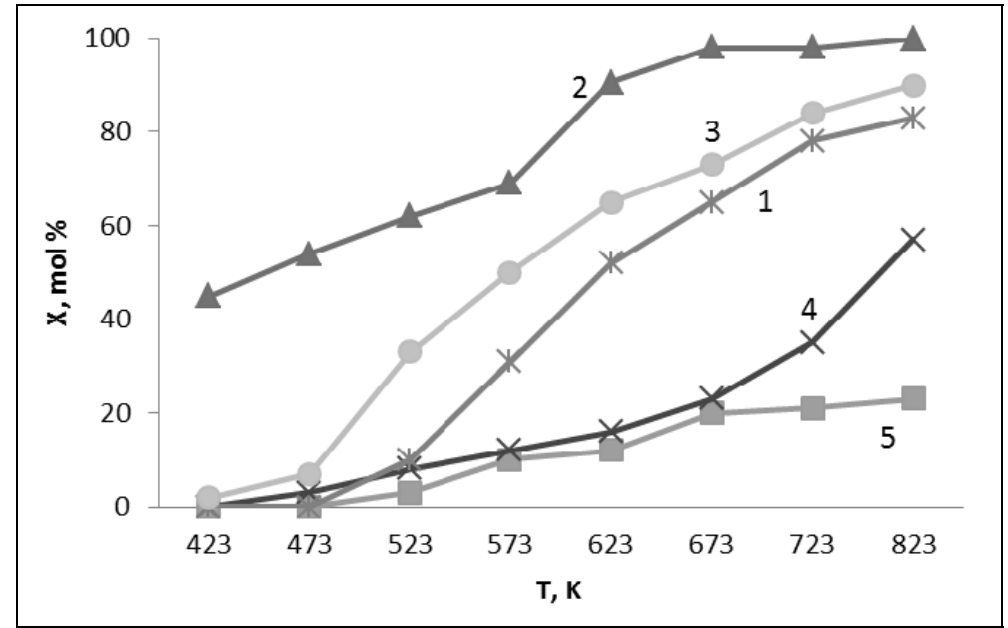

Fig. 3 The temperature dependence of converse degree in reduce of $\mathrm{NO}$ with $\mathrm{H}_{2}(1), \mathrm{CO}(2), \mathrm{NH}_{3}(3), \mathrm{CH}_{4}(4)$ and $\mathrm{NO}_{\mathrm{x}}$ decomposition (5) on CuFeDeCL.

ions have ability to displace iron from its positions, the sequence of introduction of these ions in zeolite structure does not matter. Obtained results about promoting action of $\mathrm{Fe}^{3+}$ on $\mathrm{Cu}$-exchanged zeolite are in accordance with literature data [20].

\subsection{The Influence of Ratio NO/CO on Conversion} Degree

To establish the influence of reactants NO and CO ratio on products yield, it was chosen the reaction (1) as more low-temperature, effective and practical from environmental point of view, since its realization gives possibility to clean the exhaust gases from more toxic components. The ratio of $\mathrm{NO}$ and $\mathrm{CO}$ have a meaning for way of reaction and obtained products. It was found that maximal conversion in selective catalytic reduction of $\mathrm{NO}$ was achieving at stoichiometric ratio $\mathrm{NO}: \mathrm{CO}$, equal 1:1.15. At ratio less than stoichiometric, at $573 \mathrm{~K}$ reaction carried out with intermediate formation of $\mathrm{N}_{2} \mathrm{O}$.

3.3 The Influence Specificity of Zeolite Structure and Nature of Exchange Cations on Catalytic Activity of $C L$ and $M O R$

So, the data show that acid decationation of CL and MOR results in decrease of catalytic activity, but treatment with ammonia causes the increase of activity to compare with untreated samples. The 
introduction of copper and iron ions in preliminary decationated zeolites induces increase of conversion degree of carbon and nitrogen monoxides almost on one order of magnitude, especially in interval of low temperatures. $\mathrm{CuDeCL}$ and $\mathrm{CuFeDeCL}, \mathrm{CuDeMOR}$ and $\mathrm{CuFeDeMOR}$ show maximal conversion at 423-773 K, i.e., the temperature range shifts in low temperatures. The main products of reaction (1) are molecular nitrogen and carbon dioxide, the conversion degree reaches $95 \%-98 \%$ at $673 \mathrm{~K}$. It was obtained the following line of activity for all studied samples: DeMOR $<$ DeCL $<$ MOR $<$ CL $<$ HMOR $<$ HCL $<$ $\mathrm{CuDeMOR} \leq \mathrm{CuFeDeMOR}<\mathrm{CuDeCL} \leq \mathrm{CuFeDeCL}$.

This dependence shows that though the structure and content of zeolite phase in ore $(85 \%$ in CL and $60 \%$ in MOR) influence on catalytic activity in some degree, the determining factors are the nature, location in zeolitic structure and charging state of substituting cation of transition metal.

At low temperatures, binary zeolite samples possesses more high and stable catalytic activity in interaction reaction of $\mathrm{NO}$ and $\mathrm{CO}$, than vanadium-contained, molybdenum-contained and titanium-contained catalysts. CuFeDeCL and CuFeDeMOR show high stable activity in 523-773 K temperature intervals (Fig. 4). The complete reduction of $\mathrm{NO}$ reached at $653 \mathrm{~K}$, the selectivity of reaction in regard to $\mathrm{N}_{2}$ is $88 \%-92 \%$, and it is carrying out according to scheme: $2 \mathrm{NO}+\mathrm{CO} \rightarrow \mathrm{N}_{2}\left(\mathrm{~N}_{2} \mathrm{O}\right)+\mathrm{CO}_{2}$.

\subsection{The Presumable Mechanisms of Oxidative Catalytic Reactions on Cu-Exchanged Zeolite}

Well-defined opinion about presumable mechanism of catalytic action of copper contacts in zeolite matrix in oxidative catalysis is absent in literature till now. Zeolites are characterized with non-ordered distribution of aluminum, silicon and exchanged atoms, so catalytic centers can't be homogeneous. The most of suggested mechanisms are based on oxidative and auto-reductive ability of copper ions according to scheme: $\mathrm{Cu}^{2+} \leftrightarrow \mathrm{Cu}^{+}$. According to Shutilov R. A. [21], rehydration of $\mathrm{Cu}^{+}$-containing samples does not cause direct $\mathrm{Cu}^{+}$oxidation to $\mathrm{Cu}^{2+}$, but favor in latter process when $\mathrm{O}_{2}$ is used as oxidant. The lightness of this transformation explains the specificity activity of $\mathrm{Cu}$-exchanged zeolite [22]. On the other hand, the formation of copper clusters on surface or in big channels of zeolite structure is necessary for oxidative reactions [22, 23].

Thus, it is assumed that at least part of copper ions exists as $\left[\mathrm{Cu}^{2+} \mathrm{OH}^{-}\right]^{+}$or $\left[\mathrm{Cu}^{2+} \mathrm{O}^{-}\right]^{+}$complexes at small content of substitution cations (about 0.1 mole per 1 mole $\mathrm{Al}_{2} \mathrm{O}_{3}$ ), and they are more active in oxidation reactions. $\mathrm{Cu}^{2+}$ of these complexes converted in $\mathrm{Cu}^{+}$during vacuumization or at high temperature. At high content of copper there are copper oxocations

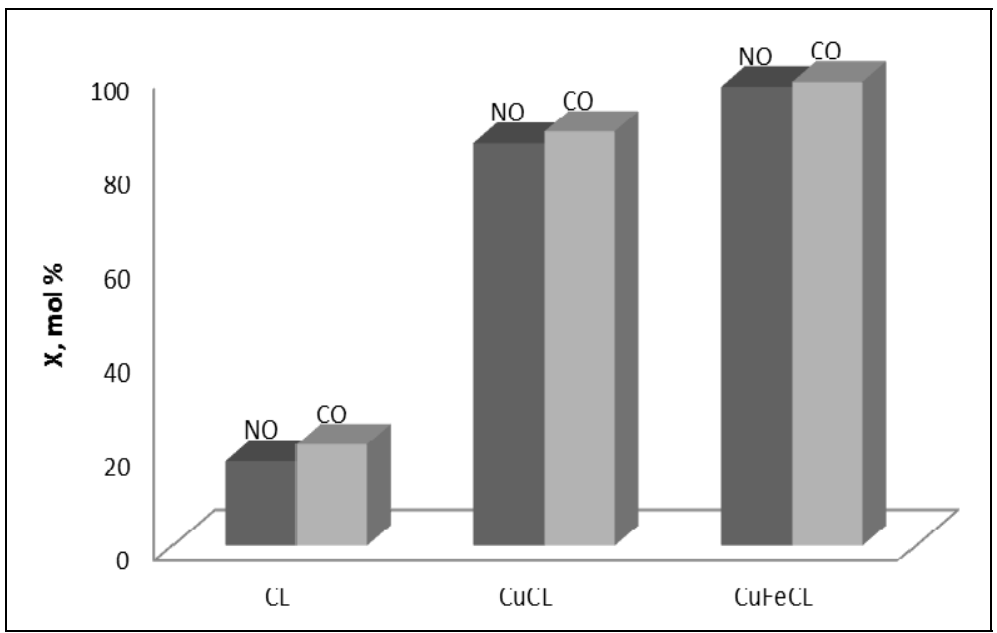

Fig. 4 The comparative activity of CL, CuDeCL and CuFeDeCL in NO and CO in joint conversion at $623 \mathrm{~K}$. 
$\left[\mathrm{Cu}^{2+}-\mathrm{O}^{2-}-\mathrm{Cu}^{2+}\right]$ in zeolite structure, which also are the active catalytic centers. The ions of $\mathrm{Fe}$ also take part in oxidation process, as similarly to copper, the transfer $\mathrm{Fe}^{3+} \leftrightarrow \mathrm{Fe}^{2+}$ easy occurs. It is supposed that reaction between $\mathrm{NO}$ and $\mathrm{CO}$ carried out in coordination sphere of these transition metals by formation of nitrozil and carbonil complexes, because of $\mathrm{Fe}^{3+}$ and $\mathrm{Cu}^{2+}$ cations, located in active cationic positions of zeolite possess the high coordinating ability that determine the catalytic activity. The implications of this coordination mode on the possible molecular mechanism of the catalytic conversion of NO over Cu-exchanged catalysts were discussed [24, 25].

\subsection{The Practical Use of Worked out Samples}

As a result of laboratory study, it was found that developed on the base of Georgian natural zeolites-CL and MOR were developed the polyfunctional catalysts with exchanged cations of copper and iron, which are characterized by properties:

- They adsorb exhaust gases at room temperature, thanks to high porosity and specific surface;

- Show more high activity and selectivity in joint conversion of $\mathrm{CO}$ and $\mathrm{NO}$ at lower temperature (420-673 K) to compare with known catalysts on the base of platinum, palladium and rhodium;

- Regeneration of used catalyst carried out by thermal treatment at $673-723 \mathrm{~K}$ in flow of dry air;

- The regime of catalyst's work-temperature of conversion beginning at $423 \mathrm{~K}$, degree of $\mathrm{NO}-45 \%$ and $\mathrm{CO}-63 \%$. At $673 \mathrm{~K}$, conversion degree of NO- $98.5 \%$ and $\mathrm{CO}-100 \%$. Products of conversion are molecular nitrogen and carbon dioxide.

Laboratory tests show that worked out copper catalyst is better than known catalysts in some parameters, such as low temperatures, regeneration ability with thermal treatment on air, action without self-heating of system, simplicity and cheapness of initial materials and preparation.
The main lack-it surrenders to existing catalysts in mechanical durability - the tablets break down under vibration. So, the principal modification is selection of according binding agent, which increases the durability without decrease of activity.

$\mathrm{CuDeCL}$ and CuDeMOR may be successfully used without binders for afterburning toxic $\mathrm{NO}$ and $\mathrm{CO}$ as the components of industrial and boilers emissions, because of the container with catalyst motionlessly fixes in ejected tube and don't undergoes to vibration.

It should be note that the method of neutralization of toxic components of exhausts gases with offered zeolite catalysts especially actual as one of ways of decision the problem of "cold start". Three-routed catalysts of automobile exhausts, which are the combination of Pt, Pd and Ro, applied on aluminum oxide or synthetic ceramic, give the possibility to decrease significantly the contamination. But they begin to work at $473-523 \mathrm{~K}$, and so far, as the temperature doesn't reaches these meanings, organic compounds, most part of which are alkenes and aromatics, don't oxidized to $\mathrm{CO}_{2}$ and $\mathrm{H}_{2} \mathrm{O}$. As a result, $60 \%-90 \%$ of exhaust generated during "cold start" when temperature on catalyst is low, turn out in atmosphere and pollute it. But zeolite catalysts as high-porous systems successfully adsorb and hold reagents until temperature rise and reduction begins.

\section{Conclusion}

It was shown that the activity of zeolitic catalysts in NO catalytic reduction with CO essentially depends on nature of cation and temperature of reaction and slightly depends on structure of zeolite and ratio of reactants. The introduction of copper and iron ions in preliminary decationated clinoptilolite and mordenite causes growth of conversion degree of nitrogen and carbon monoxides almost on a degree, especially in low temperature interval. The reaction between NO and $\mathrm{CO}$ molecules proceed in coordinative sphere of TM cations through formation of nitrosyl and carbonyl complexes. 
As regards the practical aspects of this study, the lowering temperature of the conversion of nearly 120 $\mathrm{K}$ for copper contained clinoptilolite compared to the catalysts used for post-combustion exhaust gas are the basic advantage of the studied catalysts. The method of neutralization of toxic components of exhausts gases with offered zeolite catalysts is especially actual as one way to decide the problem of "cold start".

\section{Acknowledgement}

Chemical analysis of samples was performed by Janashvili $\mathrm{N}$. and Jalagania $\mathrm{S}$. from laboratory "Geoanalytica" of TCIMR.

\section{References}

[1] Miller, T. 1996. The Life in the Environment. Moscow: High School.

[2] Kuzmina, R. I., and Sevostianov, V. P. 2000. "Catalytic Cleaning of Gas Emissions from Carbon and Nitrous Oxides.” Ross. Chim. Journal 44 (1): 71-76.

[3] Iwamoto, M., and Yahiro, H. 1994. "Novel Catalytic Decomposition and Reduction of NO." Catalysis Today 22 (1): 5-18.

[4] Grunert, W., Hayes, N. W., Joyner, R. W., Shpiro, E. S., Siddiqui, M. R. H., and Baeva, G. N. 1994. "Structure, Chemistry, and Activity of Cu-ZSM-5 Catalysts for the Selective Reduction of $\mathrm{NO}_{\mathrm{x}}$ in the Presence of Oxygen." Journal of Physical Chemistry 98 (42): 10832-10846.

[5] Sarkany, J., D'ltri J. L., and Sachtler, W. M. H. 1992. "Redox Chemistry in Excessively Ion-exchanged Cu/Na-ZSM-5." Catalysis Letters 16: 241-249.

[6] Huang, B. S., Chen, H. Y., Chuang, K. H., Yang, R. X., and Wey, M. Y. 2012. "Hydrogen Pyrrolidone on Microwave Polyol Process of Carbon-Supported $\mathrm{Cu}$ Catalysts for CO Oxidation." Applied Catalysis General 397 (1-2): 234-240.

[7] Alhazov, T. G., and Gasan-Zade, G. Z. 1981. "Catalytic Reduction of Nitrous Oxide with Carbon Oxide on Transition Metals' Oxides." Problems of Kinetics and Catalysis, Deep Catalytic Oxidation of Hydrocarbons 18: 120-124.

[8] Cubasov, A. A. 2000. "Zeolites in Catalysis: Today and Tomorrow.” Soros Educational Journal 6 (6): 44-51.

[9] Ishihara, Tu., Anami, K., Takiishi, K., Yamada, H., Nishiguchi, H., and Takita Y. 2003. "Direct Decomposition of $\mathrm{NO}$ on $\mathrm{Cu}$-Doped $\mathrm{La}(\mathrm{Ba}) \mathrm{Mn}(\mathrm{In}) \mathrm{O}_{3}$ Perovskite Oxide under Co-existence of $\mathrm{O}_{2}, \mathrm{H}_{2} \mathrm{O}$ and
$\mathrm{SO}_{3}$. ." Chem. Lett. 32 (12): 1176-1177.

[10] Farrauto, R. J., and Heck, R. M. 1999. "Catalytic Converters: State of Art and Perspectives." Catal. Today 51 (3-4): 351-360.

[11] Ostroushko, A. A., Shubert, E. I., and Juravleva, L. I. 2000. "Synthesis, Phisico-Chemical and Catalytic Properties of Perovskites $\mathrm{ABO}_{3} \pm$ y (A: La, SrJ, Ag; B: $\mathrm{Mn}, \mathrm{Co}, \mathrm{Fe}, \mathrm{Cu}, \mathrm{Ti}$, Mo and V).” Jurn. Prikladnoi Chimii. 73 (8): 1311-1320.

[12] Iashnik, C. A. 2004. "The Study of Selective Catalytic Reduction of NO with Propane and Feature of Copper Electronic State in Cu/ZSM-5 Catalysts." Ph.D. thesis, Boreskov Catalysis Institute.

[13] Valyon, J., and Hall, W. K. 1993. "On the Preparation and Properties of Cu/ZSM-5 Catalysts for NO Decomposition." Catal. Letters 19 (2-3): 109-119.

[14] Bulanek, R., Wichterlova, B., Sobalik, Z., and Tichy, J. 2000. "Reducibility and Oxidation Activity of $\mathrm{Cu}$ Ions in Zeolites, Effect of $\mathrm{Cu}$ Ion Coordination and Zeolite Framework Composition." Appl. Catal. B: Enviromental 31 (1): 13-25.

[15] Sidamonidze, Sh., Akhalbedashvili, L., and Chanrvetadze, B. 1985. "Catalytic Activity of Clinoptilolite in Nitrogen Oxide Conversion." Vestn. Slov. Kem. Drus. 32 (3): 263-272.

[16] Akhalbedashvili, L., and Sidamonidze, Sh. 2001. "Modified Natural Zeolites in Catalytic Clearing of Exhaust and Ejected Gases from Nitric and Carbon Oxides." In Proc. of 13th International Conference on Zeolites, 135.

[17] Mskhiladze, A., Maisuradze, G. I., Sidamonidze, B. G. and Chankvetadze, Sh. I. 2010. "Catalytic Neutralizers for Exhaust and Ejection Gases' Purification from Nitrogen and Carbon Oxides." Georgia Chemical Journal 10 (4): 76-78.

[18] Akhalbedashvili, L., Maisuradze, G., Mskhiladze, A., and Sidamonidze, Sh. 2013. "About Possibility of Using Modified Clinoptilolite in Catalytic Cleaning of Exhaust Gases from NO and CO." In 17th International Zeolite Conference, 251-252.

[19] Doronkin, D. E., Kucherov, A. V., and Bragina, G. O. 2009. "Nature of Active Sites of Fe-Beta Catalyst for NO-SCR by $\mathrm{NH}_{3}$." Top. Catal. 52 (13): 1728-1733.

[20] Doronkin, D. E. 2010. "Fe-Zeolite Catalysts of Selective Reducing $\mathrm{NO}_{\mathrm{x}}$ with Ammonia." In Dissertation for the Degree of Candidate of Chemical Sciences, 104.

[21] Shutilov, R. A. 2012. "State and Localization of Copper-Contained Component in Cu/ZSM-5 Catalysts and Their Influence on Catalytic Properties in Nitrogen Oxides Conversion Reactions." In Dissertation for the Degree of Candidate of Chemical Sciences, 149.

[22] Gemma Turnes Palomino, Paola Fisicaro, Silvia Bordiga, 
and Adriano Zecchina. 2000. "Oxidation States of Copper Ions in ZSM-5 Zeolites: A Multitechnique Investigation." J. Phys. Chem. B 104 (17): 4064-4073.

[23] Chmielarza, L., Kuśtrowskia, P., Dziembaja, R., Coolb, P., and Vansantb, E. F. 2010. "SBA-15 Mesoporous Silica Modified with Metal Oxides by MDD Method in the Role of $\mathrm{DeNO}_{\mathrm{x}}$ Catalysts." Microporous and Mesoporous Materials 127 (1-2): 133-141.
[24] Ramprasad, R. 1997. "Density Functional Study of NO Decomposition on Cu-Exchanged Zeolites." Ph.D. thesis, University of Illinois at Urbana-Champaign.

[25] Zbigniew Sojka, and Michel Che. 1997. "EPR Investigation of the Electronic Structure of Mononuclear Copper(I) Nitric Oxide Adduct Formed upon Low-Pressure Adsorption of NO onto Cu/ZSM-5 Zeolite.” J. Phys. Chem. B 101 (24): 4831-4838. 